\title{
A voz de gestores municipais sobre o acesso à saúde nas práticas de gestão
}

\author{
The voice of municipal administrators on access to health \\ in management practices
}

Bela Feiman Sapiertein Silva ${ }^{1}$ Gladys Amelia Vélez Benito ${ }^{2}$

${ }^{1}$ Secretaria Estadual de Saúde do Estado do Espírito Santo. Av. Manoel Pessanha 360, Boa Vista. 29931-420 Vitória ES.

belasilva@saude.es.gov.br ${ }^{2}$ Departamento de Ciências da Saúde, Universidade Federal do Espírito Santo.
Abstract Universal access to health services is a challenge for municipal administration in a society that treats health as a commodity and gives preference to the individual consumer to the detriment of the citizen. This study sought to identify the social representations in the narrative of local health managers in a micro-region of southeast Brazil about access to health services. It consists of qualitative research with interviews conducted with 16 managers. The Collective Subject Discourse technique was employed with the use of Qualiquantisoft software in the data analysis. Four core ideas were identified: coordination between federal states; reorganization of admission procedures; user service and the precariousness of guaranteed access. It was revealed that the quality, resolvability, approach to the user's needs and the care network organization are poorly addressed, which reflects an understanding that does not consider 'access quality and resolution.' It is understood that the managers' impotence to make changes and the lack of society and worker engagement in management bolster the supremacy of market interests and contribute to 'limited access' and the continuity of the hegemonic model of care.

Key words Health service access, Health management, Unified Health System
Resumo O acesso universal aos serviços de saúde é um desafio para a gestão municipal numa sociedade em que apresenta a saúde como mercadoria e privilegia o indivíduo consumidor em detrimento do cidadão. O estudo teve como objetivo reconhecer as representações sociais presentes na narrativa das práticas dos gestores municipais de saúde de uma microrregião do sudeste do Brasil sobre o acesso aos serviços de saúde. Trata-se de pesquisa qualitativa mediante entrevista com 16 gestores. $\mathrm{Na}$ análise, utilizou-se a técnica do Discurso do Sujeito Coletivo, com o auxílio do programa Qualiquantisoft. Identificaram-se quatro Ideias Centrais: articulação interfederativa; reorganização da porta de entrada; atendimento ao usuário; $e$, fragilidade para a garantia de acesso. Constatouse que a qualidade, resolutividade, aproximação com as necessidades do usuário e organização das redes de atenção são pouco expressas, o que reflete um entendimento que não leva em consideração o 'acesso de qualidade e resolutivo'. Compreende-se que a impotência apresentada pelos gestores para gerar mudanças e a falta de participação da sociedade e dos trabalhadores na gestão fortalecem a supremacia dos interesses do mercado e contribuem para a garantia de um 'acesso limitado' e a manutenção do modelo de atenção hegemônico. Palavras-chave Acesso aos serviços de saúde, Gestão em saúde, Sistema Único de Saúde 


\section{Introdução}

A construção do Sistema Único de Saúde como Sistema de Saúde brasileiro, instituído em 1988, se dá por meio de constante tensão entre os princípios idealizados pelo movimento da Reforma Sanitária e o contexto contemporâneo, que se apresenta como a proposta hegemônica vigente. Nesse sentido, torna-se um desafio a garantia da saúde como direito de todos em uma sociedade que transforma o cidadão em um agente consumidor e a saúde em mercadoria.

Para Bauman ${ }^{1}$ o sujeito consumidor precede o sujeito cidadão, de forma que há distinção entre o 'consumidor eficiente' ou o 'consumidor falho'. Nesta diferenciação, valoriza-se aquele que é capaz de ter acesso aos produtos disponíveis no mercado para atender não só suas necessidades e desejos, mas também para garantir o fluxo ininterrupto de produção e descarte que impulsiona a sociedade de consumidores. A saúde assume uma característica de produto disponível no mercado acessível para o 'consumidor eficiente', opondo-se ao seu caráter de direito universal e ainda, aponta obstáculos para a garantia de acesso com qualidade e efetividade aos serviços de saúde. Neste contexto, a descentralização é a única diretriz do SUS que vai ao encontro tanto das propostas do Movimento Sanitário quanto da sociedade contemporânea, apesar das bases ideológicas de cada uma serem distintas ${ }^{2-4}$.

O Movimento Sanitário defende a descentralização como uma possibilidade para a redemocratização do país na medida em que aproxima os serviços às necessidades do cidadão e possibilita a ampliação da participação social. Já o projeto político econômico vigente defende a descentralização na medida em que contribui para a redução do papel do Estado em nível nacional e compartilha as responsabilidades com a sociedade e o mercado ${ }^{2-4}$. Esse interesse duplo facilitou o avanço do processo de descentralização, porém segundo Spedo et al. " "foram construídos sistemas municipais com distintos potenciais resolutivos, atomizados e desarticulados, independente da capacidade de governo dos municípios para assumir esse papel”. Desta forma, apesar da ampliação do acesso possibilitada pela descentralização, esta não contribuiu para a redução das desigualdades na produção de serviços entre os municípios, conforme aponta Arretche ${ }^{5}$.

De acordo com Mendes ${ }^{6}$ havia a suposição de que o processo de descentralização aumentaria a eficiência e a transparência das políticas públicas na medida em que aproximasse as deci- sões públicas dos cidadãos; no entanto, apesar dos avanços, como a ampliação da oferta local de serviços e da autonomia dos estados e municípios, tanto Arretche ${ }^{5}$ quanto Mendes $^{6}$ acreditam que não há evidências de que a descentralização para os governos locais tenha garantido maior eficiência e responsabilidade.

Se para a esfera federal a descentralização de responsabilidades, é uma posição confortável, pois se 'livra' do ônus político, social e econômico que representa a saúde e a previdência ${ }^{7}$, para os municípios torna-se um 'peso difícil de ser carregado', pois, como Mendes ${ }^{6}$ afirma "as demandas sociais são levadas, mais proximamente, pelos cidadãos, aos estados e municípios que, contudo, têm menores capacidades fiscais para atendê-las". A partir desta situação, acreditamos que o cidadão acaba sendo o maior prejudicado, pois a saúde que é um direito constitucionalmente garantido, não é assumida efetivamente por nenhuma esfera governamental.

É interessante destacar ainda que a Lei Orgânica $\mathrm{n}^{\circ} .8 .080 / 90^{8}$ em seu artigo $8^{\circ}$ afirma que as ações e os serviços de saúde executados diretamente ou com a participação complementar da iniciativa privada, deverão ser organizados de forma regionalizada e hierarquizada em níveis de complexidade crescente. Desta forma, a regionalização é apresentada como macroestratégia para avançar no processo de descentralização em saúde, visando garantir o acesso aos usuários e a oferta de serviços resolutivos e de boa qualidade em todos os níveis de atenção ${ }^{9}$.

As Normas Operacionais de Assistência à Saúde (NOAS) apresentam o Plano Diretor de Regionalização (PDR) e determinam que seja da responsabilidade das Secretarias Estaduais de Saúde a sua elaboração com o objetivo de garantir acesso aos serviços e ações de saúde para o cidadão o mais próximo de sua residência. Dessa forma, segundo Vasconcelos e Pasche ${ }^{10}$ a dificuldade para a efetivação do PDR cria um impasse para a gestão municipal que por não conseguir assegurar o acesso da população a serviços especializados acaba por buscar uma autossuficiência. Esta ação contribui para a oferta de uma atenção básica não resolutiva e de baixa qualidade e uma alocação dos recursos financeiros ineficientes.

Fica evidente, conforme destaca Trevisan e Junqueira ${ }^{11}$ que o processo de descentralização e regionalização exige um 'pacto de gestão' que envolve um processo de divisão decisória e de poder, sendo estes processos prioritários para que os tomadores de decisão não percam a visão integral da saúde e o respeito pelo cidadão de forma 
que "é preciso ter absoluta clareza que não existe o doente federal, estadual, municipal ou comunitário. Existe o cidadão que está exercendo o direito constitucional de ter acesso à saúde [...]".

Em relação ao âmbito intramunicipal, o SUS, apresenta a proposta de reorganização da atenção à saúde com ênfase na atenção primária. $\mathrm{O}$ Programa de Saúde da Família (PSF) é apresentado como uma estratégia para ampliação do acesso aos serviços de saúde. A proposta referese a uma primeira fase do programa que avança desde a sua implantação até $1996^{12,13}$. Em 2007, o PSF, já com a denominação de Estratégia de Saúde da Família (ESF), assume sua segunda fase na qual é entendida como um novo modo de reorganizar a rede básica e uma estratégia de transformação do modelo assistencial ${ }^{12-13}$.

Algumas críticas são apontadas à ESF, dentre elas, Merhy e Franco ${ }^{14}$ apontam que a implantação da estratégia não muda necessariamente o processo de trabalho centrado nas tecnologias duras visto que a formação da equipe, a territorialização e o incentivo ao trabalho de vigilância à saúde, apesar de darem uma ideia de mudança no modo de produzir saúde, mantêm o núcleo do cuidado na lógica instrumental realizado a partir de atos prescritivos.

Para os mesmos autores ${ }^{14}$ as tecnologias duras referem-se a equipamentos, instrumentos e outros artigos materiais utilizados para diagnósticos e tratamentos enquanto que as tecnologias leves referem-se às relações construídas entre duas pessoas (usuário e profissional/equipe) em ato. Eles concluem ainda que, apesar de algumas mudanças em curso não há uma alteração no modelo assistencial hegemônico sem uma mudança na centralidade dada às tecnologias duras com vistas à valoração da tecnologia leve no processo produtivo.

Diante do exposto, entendemos que a garantia do acesso aos diversos níveis de atenção à saúde é um desafio para a gestão municipal. Ainda, entendemos que para compreender a forma como a gestão se organiza para garantir esse acesso se apresenta nas próprias práticas e que gestores agem e direcionam suas ações a partir do contexto em que estão inseridos, dos locais que ocupam nesta realidade e consequentemente das representações sociais que constroem em relação aos vários aspectos que envolvem o encaminhamento das ações de saúde.

Assim, apresentamos um estudo que se propõe reconhecer as representações sociais presentes na narrativa das práticas dos gestores municipais de saúde que atuam em alguns municípios da região sudeste do Brasil sobre o acesso aos serviços de saúde.

\section{Metodologia}

Trata-se de um estudo exploratório pautado em uma abordagem qualitativa. Os sujeitos da pesquisa foram 16 (dezesseis) secretários de saúde que atuam em nove municípios que compõe a microrregião São Mateus (ES), provenientes de dois grupos. O primeiro refere-se aos 9 (nove) secretários de saúde em exercício, independente do período que este esteja no cargo e o segundo aos 7 (sete) secretários de saúde da gestão anterior (2005-2008) que se mantiveram no cargo por mais tempo no referido período.

A coleta de dados se deu a partir de um questionário com perguntas de caracterização dos sujeitos pesquisados e um roteiro semiestruturado. O método de análise utilizado, criado por Lefevre e Lefevre ${ }^{15}$, foi o Discurso do Sujeito Coletivo (DSC) que são discursos-sínteses redigidos na primeira pessoa do singular, composto por expressões chaves $(\mathrm{ECH})$ - trechos mais significativos de cada depoimento - que têm a mesma ideia central (IC) e/ou ancoragem. Busca a reconstituição discursiva da(s) representação(ções) social(is) de uma coletividade como se esta fosse a emissora de um discurso.

Para auxiliar no processamento dos depoimentos e na construção dos DSC foi utilizado o programa Qualiquantisoft, versão $1.3 \mathrm{c}$, desenvolvido na Faculdade de Saúde Pública da Universidade São Paulo (USP) por Lefevre e Lefevre em parceria com Sales \& Paschoal Informática.

Foram atendidas as prerrogativas da Resolução no 196/96, do Conselho Nacional de Saúde para Pesquisa Científica em Seres Humanos ${ }^{16}$; sendo aprovado pelo Comitê de Ética em Pesquisa (CEP) da Universidade Federal do Espírito Santo.

\section{Resultados}

A caracterização dos sujeitos pesquisados apresenta um grupo de gestores municipais com o mesmo número de homens e mulheres, com idade que varia entre 27 a 58 anos, com predomínio da faixa etária entre 36 a 47 anos. Em relação ao grau de escolaridade, $93,75 \%$ possuem nível superior completo e dentre estes, $66,67 \%$ possuem pós-graduação, com ênfase em especialização em APS, Gestão em Saúde e em Políticas Públicas. 
Quanto a experiência profissional, 81,2\% já atuaram na área da saúde; $62,5 \%$ já tiveram experiência em cargo de gestão, prioritariamente em serviço de saúde e ainda e $81,2 \%$ afirmam estar no cargo há mais de 1 ano. Em sua maioria, estes possuem experiência tanto acadêmica quanto profissional na área da saúde, na área de gestão ou em ambas. Confirma-se ainda, uma fragilidade dos vínculos empregatícios, na medida em que $75 \%$ possuem apenas vínculo temporário.
Foram encontradas quatro Ideias Centrais que são as sínteses do conteúdo manifestado nas ECH selecionadas. Cabe esclarecer que para algumas IC foram construídos mais de um DSC por entender que as ECH apresentavam representações distintas apesar de todos apontarem a mesma IC. Segue abaixo o Quadro 1 que apresenta as IC e os respectivos DSC que discutiremos mais adiante.

Quadro 1. Discurso do Sujeito Coletivo em relação ao acesso aos serviços de saúde.

\begin{tabular}{|c|c|}
\hline Ideia Central - 1 & Discurso do Sujeito Coletivo - 1 \\
\hline $\begin{array}{l}\text { Articulação } \\
\text { interfederativa }\end{array}$ & $\begin{array}{l}\text { Os exames especializados, têm casos que você não tem como atender porque a demanda é } \\
\text { maior do que o recurso nas mãos e muita coisa nem é que a gente não queria pagar, você não } \\
\text { consegue. Então muita coisa você fica na puxa vida não consegui! Aí que vem os incêndios que } \\
\text { também surgem em função da rede não estar totalmente estruturada. As questões, as } \\
\text { pactuações, as questões das responsabilidades, o que é de competência do Estado, por } \\
\text { exemplo, que por mais que se trabalhe uma atenção primária certinha, planejadinha, } \\
\text { organizadinha, há um momento em que a gente vai depender da atenção secundária. Hoje se } \\
\text { não fizer um pré-natal bom, se necessitarmos de uma estrutura, de uma referência de média } \\
\text { e alta complexidade, de UTIN, de uma maternidade de alto risco, hoje o que? Hoje não tem. } \\
\text { Até porque por ser um município do tamanho deste, você não ter como garantir o acesso a } \\
\text { todos os serviços, quando vocế vai bater à porta de outros, nós esbarramos em questões muito } \\
\text { sérias, ninguém quer assumir, entendeu? Quando nós conversamos nas reuniões de CIB né, } \\
\text { reunião do COSEMS parece, a minha percepção assim, posso tar enganada, é o que nós, } \\
\text { municípios do norte, a gente tá meio que esquecido, igual as redes, oficinas maravilhosas, mas } \\
\text { algumas coisas não saíram do papel. Sabe, tem pessoas que estão morrendo, vai esperar } \\
\text { morrer? Eu acho que os secretários do extremo norte deveria unir e tar cobrando assim, tar } \\
\text { fazendo um, conselho forte, uma CIB mais forte. }\end{array}$ \\
\hline Ideia Central - 2 & Discurso do Sujeito Coletivo - 2 \\
\hline \multirow[t]{3}{*}{$\begin{array}{l}\text { Reorganização da } \\
\text { porta de entrada } \\
\text { aos serviços de } \\
\text { saúde }\end{array}$} & $\begin{array}{l}\text { DSC 2A - PSF como porta de entrada dos serviços de saúde: Uma coisa que nós fizemos, } \\
\text { por exemplo, colocamos lá na frente do hospital pra poder ser atendido no hospital só em caso } \\
\text { de urgência, forçando um pouquinho entre aspas a população a ir pras equipes de saúde da } \\
\text { família. Outra coisa, que no início criou muita reclamação, até pra ir pro pediatra tem que } \\
\text { ter referência do médico da Saúde da Família. [...] nós hoje reduzimos pelo menos } 60 \% \text { da } \\
\text { demanda de hospital indo para os PSF. Isso é importante porque: primeiro, hoje se a gente } \\
\text { for querer colocar tudo dentro do hospital, não dá conta e segundo, que você mistura o tipo de } \\
\text { atendimento, quer dizer, hospital nunca vai pensar a saúde como promoção, proteção e } \\
\text { prevenção, vai pensar só como recuperação. Hospital não é pra esta finalidade [...]. Então, a } \\
\text { parte de conscientização e orientação é muito intensificada, pela necessidade até da } \\
\text { implantação da saúde da família, porque a gente tá saindo de uma demanda completamente } \\
\text { espontânea pra uma demanda programada e isso é muito difícil de quem tá lá entender [...]. }\end{array}$ \\
\hline & $\begin{array}{l}\text { DSC 2B - PSF como porta de entrada para encaminhar os problemas da população: [...] eu } \\
\text { não tô pensando só, que o PSF é porta de entrada porque o usuário tem que procurar em } \\
\text { primeiro lugar o PSF não, a porta de entrada da saúde porque o PSF ele tem que visualizar } \\
\text { tudo o que tem que ser resolvido naquele território ali, é ele que tem que direcionar pro poder } \\
\text { executivo o que tem que ser feito pra melhorar a saúde daquela população, daquele território } \\
\text { [...]. }\end{array}$ \\
\hline & $\begin{array}{l}\text { DSC 2C - Urgência e emergência como porta de entrada dos serviços de saúde: Nós temos } \\
\text { um problema no município: os médicos não atendem às } 40 \text { horas semanais que é obrigatório } \\
\text { do PSF, então é onde as pessoas vão procurar o hospital. Então, na prática, não no ideal, o } \\
\text { hospital ele se tornou um grande ambulatório [...]. A própria população procura o PA, } 90 \% \\
\text { do pessoal aqui vem no Pronto Atendimento [...]. }\end{array}$ \\
\hline
\end{tabular}


Quadro 1. continuação

\begin{tabular}{|c|c|}
\hline & $\begin{array}{l}\text { DSC 2D - Outras alternativas como porta de entrada dos serviços de saúde: Além do } \\
\text { atendimento diário do PSF, à tarde nós contratamos profissionais médicos pra atender de } 4 \\
\text { horas até às } 9 \text { horas da noite. Nosso município é agrícola, então são trabalhadores da área } \\
\text { rural e muitas vezes não podem matar dia de serviço pra vir numa consulta, então nós } \\
\text { atendemos esse horário pra dar uma sustentação a essas pessoas que necessitam de um } \\
\text { médico e se não, iam recorrer ao hospital [...]. A gente tá fazendo um atendimento } \\
\text { diferenciado levando um médico na comunidade, quando a gente não pode fazer um } \\
\text { atendimento pelo PSF e nós temos outros especialistas aí que fazem o atendimento e a } \\
\text { demanda pode ser encaminhada pelo PSF ou demanda livre [...]. }\end{array}$ \\
\hline & $\begin{array}{l}\text { DSC 2E - Dificuldades para efetivação do PSF/ESF como porta de entrada: Infelizmente tá } \\
\text { faltando médico, eu acho que poucos quer vir para o interior [...]. O nosso maior desafio é } \\
\text { fixar esse profissional, com que ele fique satisfeito, parar com essas questões de briga, } \\
\text { município oferecendo mais e aí a gente perde todo o trabalho. E hoje, por imposição de uma } \\
\text { proposta de governo pra saúde de trabalhar atenção primária através das equipes de PSF, } \\
\text { eles tão vindo atraídos pelos salários quer queira quer não e eu acho que a gente tá tapando } \\
\text { sol com a peneira [...]. Eu acho que há ainda um longo caminho a seguir em virtude que } \\
\text { muitos profissionais, principalmente profissionais médicos mais antigos, não entenderam } \\
\text { ainda qual é a psicologia da ESF de priorizar programas, priorizar prevenção [...]. Uma coisa } \\
\text { que nós temos dificuldade é a questão de demanda por agenda, porque o povo ainda tem a } \\
\text { visão de que, tipo assim, eu chegar e eu ser atendido na hora né. Também tem a pressão dos } \\
\text { médicos do hospital, da propaganda contrária do PSF e isso ai é público, todo mundo sabe } \\
\text { [...]. O modelo que fica realmente é o modelo hospitalocêntrico. Posso ter todas as equipes de } \\
\text { PSF, olha que a minha cobertura é muito boa, mas se eu não tenho um médico plantonista } \\
24 \text { horas, todo aquele trabalho ali é considerado inválido. }\end{array}$ \\
\hline Ideia & Discurso do Sujeito Coletivo - 3 \\
\hline $\begin{array}{l}\text { Atendimento } \\
\text { direto ao usuário }\end{array}$ & $\begin{array}{l}\text { Na verdade o dia a dia do secretário, ele é bastante puxado em relação à demanda porque } \\
\text { na verdade, você chega na secretaria: é aquela fila de gente que não conseguiu remédio, o } \\
\text { carro que não pode levar, a consulta que foi desmarcada. [...]. Eu acho que o atendimento ao } \\
\text { público, as pessoas confundem com assistencialismo, aí começa a comparação de que na outra } \\
\text { cidade é assim, é uma pressão, uma pressão psicologica e eu acredito que não é só aqui [...]. } \\
\text { Uma das coisas que a gente percebeu é que quanto mais você atende mais gente tem pra } \\
\text { atender e eu vejo que aqui também eu estou contribuindo pra diminuir o sofrimento daquelas } \\
\text { pessoas lá na ponta e me sinto bem, porque quando a gente consegue uma coisa, } \\
\text { principalmente uma cirurgia, que é difícil, ou uma cirurgia eletiva ou uma cirurgia } \\
\text { oftalmológica, a gente tenta ter uma visão de como se fosse a gente precisando do serviço. }\end{array}$ \\
\hline Ideia Central - 4 & Discurso do Sujeito Coletivo - 4 \\
\hline $\begin{array}{l}\text { Fragilidade para a } \\
\text { garantia de acesso }\end{array}$ & $\begin{array}{l}\text { Mas às vezes você é tolhida de umas açães por causa das decisões políticas. Por exemplo, você } \\
\text { tem x vagas, ai politico de cá, o deputado, senador, aí alguém que conhece aí atravessa, entra } \\
\text { na frente e as vagas são ocupadas dessa maneira, pela janela e não pela via normal. Mas } \\
\text { teve momentos que nós usamos desse serviço também, de indicação, de depender da } \\
\text { influência politica pra poder conseguir um atendimento ali que era urgente e a gente não } \\
\text { tinha como. Outra coisa que acontece hoje, acaba outras pessoas que não são do município } \\
\text { sendo atendida, o SUS é pra todos, mas aí você atende aquele cidadão que não é do seu } \\
\text { município e deixa de entender de forma integral um que é do seu. E ainda tem a questão da } \\
\text { judicialização que interfere negativamente na integralidade, porque eles furam a fila, eles } \\
\text { querem se livrar do problema que tá na frente deles e porque hoje no Brasil uma coisa que é } \\
\text { muito complicada é o lobby da indústria farmacêutica. A gente sofre muito com isso né, e se o } \\
\text { médico disser pra você que você tem que tomar o remédio x e eu só tenho y que é similar ao } \\
\text { seu x, mas você quer o x e o juiz não entender, então eu vou pagar muito mais caro por um } \\
\text { desconhecimento. Até porque a partir do momento que a pessoa acha que não tem acesso ao } \\
\text { serviço de saúde automaticamente ela tá fora da integralidade, não tá atingindo as suas } \\
\text { necessidades que ela acha importante. }\end{array}$ \\
\hline
\end{tabular}




\section{Discussão}

O DSC 1 apresenta as articulações interfederativas como a maior fragilidade percebida pelos gestores para a efetivação dos princípios do SUS. Expressa as dificuldades dos municípios para garantir acesso da população a serviços de média e alta complexidade e a efetivação das redes de atenção, em decorrência do Estado não assumir a sua responsabilidade quanto à oferta de serviços que estão sob sua competência, o que faz com que muitas vezes a gestão municipal seja obrigada a assumir serviços que não são de sua competência.

O discurso ainda expressa que as falhas do Estado reafirmam a necessidade de se investir na atenção primária a fim de que ela seja resolutiva e assim, se reduza os encaminhamentos para os serviços de maior complexidade.

Porém, esta proposta produz uma reflexão em duas vertentes. A primeira está relacionada ao fator que motiva o gestor a investir na atenção primária. Seria a necessidade de reduzir os encaminhamentos para serviços de maior complexidade? Ou estaria relacionada à percepção da atenção primária enquanto um caminho para uma mudança nas condições de saúde da população? A segunda reflexão refere-se ao desafio do gestor se produzir em investir um único e reduzido recurso tanto na atenção primária quanto nos demais níveis de atenção visto que o discurso aponta para a necessidade de investimentos em ações que não estão sob sua responsabilidade. Essa questão, já apontada por Vasconcelos e Pasche ${ }^{10}$ pode comprometer o investimento na atenção primária e contribuir para a manutenção do sistema vigente.

Entendemos que a fragilidade das articulações interfederativas é um reflexo da do processo de descentralização da política de saúde do país que não levou em consideração as especificidades e as condições locais e regionais, enfraqueceu o papel das Secretarias Estaduais de Saúde e distanciou a esfera federal dos serviços de saúde.

Apesar dos avanços previstos no Pacto pela Saúde no que se refere às responsabilidades de cada esfera, entendemos que apenas a descentralização embasada na transferência de responsabilidades e de recursos financeiros (escassos) para o nível municipal não garante por si só o fortalecimento da capacidade administrativa e institucional dos mesmos, assim como também não garante um acesso com qualidade a uma atenção integral.

O discurso expressa que há dificuldades para os municípios da região em estudo garantir o acesso da população aos serviços de média e alta complexidade e aponta como algumas de estas causas, o tamanho dos municípios e o esquecimento da referida região por parte tanto do Estado quanto dos demais municípios. Esta situação contribui para fragilizar o âmbito municipal, mantendo-o subordinado às determinações dos outros entes federados. Exala a representação historicamente construída de uma relação verticalizada que ainda não foi superada, apesar das mudanças garantidas formalmente pelo SUS. O discurso aponta para a necessidade de se fortalecer a organização da saúde de forma regionalizada e para tanto, torna-se necessário rever o sentido atribuído aos espaços formais de pactuação e negociação e, a forma como os gestores se posicionam e se articulam nestes espaços.

Nesse sentido, o discurso aponta para uma reflexão sobre o protagonismo dos gestores municipais no processo de consolidação do SUS, a necessidade de haver maior união entre os municípios e de fortalecer os espaços formais de negociação e representação para melhorar os serviços prestados e facilitar desta forma, o acesso da população aos mesmos.

Entendemos ser necessário o fortalecimento desses espaços com vistas à melhoria de uma relação mais horizontal ao fortalecimento de uma relação horizontal, cooperativa e de cogestão interfederativa. Para tanto, o estado e os municípios deverão assumir o papel de protagonista e de corresponsáveis não só pela garantia de acesso, mas pela condução da política de saúde regional, sem uma transferência mútua de responsabilidades. No entanto, essa proposta vai na contramão de uma sociedade de consumidores que estimula as relações competitivas, a transferência de responsabilidades e os interesses individuais em detrimento de interesses coletivos.

O discurso ainda aponta para a representação de que a relação interfederativa é tensa e de disputa e que os municípios somente conseguirão mais espaço de negociação mediante um embate de poderes instituídos e instituintes. Para nós, a fragilidade de articulação interfederativa, bem como a atuação ainda assumida pelos gestores municipais envolvidos na pesquisa que prioriza a execução das políticas em detrimento da coconstrução das mesmas, mostra-se como mais um desafio a ser enfrentado por todos os atores envolvidos no âmbito da saúde.

Já o DSC 2 sobre a 'reorganização da porta de entrada dos serviços de saúde' aponta uma preocupação dos gestores em garantir o acesso dos serviços de saúde à população. Para a mesma IC, 
foram construídos cinco DSC (Quadro 1), descritos abaixo:

O DSC 2A apresenta a ESF como porta de entrada para os serviços de saúde e aponta para a necessidade de criação de estratégias impositivas para a efetivação da proposta, refletindo uma representação de que o gestor é o detentor do poder e do saber, o que lhe confere a capacidade de definir o que é melhor para a população e a melhor forma de organizar os serviços. Já o DSC 2B expressa uma função para a equipe de saúde da família que extrapola o âmbito das unidades de saúde e volta-se para a melhoria das condições de vida da população e para tanto, prioriza a responsabilização da equipe por uma população adscrita.

Ainda que os dois discursos apontem entendimentos diferenciados para a ESF enquanto porta de entrada para o sistema, nenhum expressa a participação da população como sujeito do processo de decisão da referida estratégia. Ao se referir à população, o DSC $2 \mathrm{~A}$ apresenta ações educativas ou de conscientização direcionadas à população, porém a representação do gestor aponta para a 'concepção bancária da educação' na qual o 'educador' apresenta as informações e o 'educando' apenas memoriza e arquiva, conforme aponta Freire ${ }^{17}$. Nesse caso, as informações são transmitidas de forma verticalizada e antidialógica de forma que reproduz a uma educação para a passividade e acrítica ${ }^{17}$.

Já o DSC 2B confere para a equipe de saúde da família a responsabilidade de detectar e encaminhar as necessidades da população. A participação dessa tanto para definir suas necessidades quanto para reivindicar seus direitos não é citada. Aponta assim, para a representação de uma população tutelada e uma relação paternalista. A representação presente nos dois discursos em relação à participação da população apresenta-se contrária a proposta apresentada pela 'Promoção da Saúde’ a qual está centrada no fomento da autonomia e do empoderamento da população.

No que se refere a outras portas de entrada, o DSC 2D cita os ambulatórios de especialidades como possibilidades para a porta de entrada ao serviço de saúde, sem valorizar a inter-relação com a ESF. Por outro lado, ao fazer referência à APS em diversos DSC, afirmam a importância da mesma para encaminhamentos para os serviços de média e alta complexidade.

Diante do exposto, entendemos que na representação do gestor os níveis de atenção denominados de média e alta complexidade, por si só, respondem as necessidades de saúde, assim não é necessária a articulação com a APS. Porém, esta é insuficiente para alcançar esse objetivo, necessitando da complementação garantida pelos outros níveis de atenção. Acreditamos que o discurso reforça um modelo centrado nos procedimentos clínicos, com ênfase nas especialidades.

Em relação aos serviços hospitalares e de pronto atendimento como porta de entrada aos serviços de saúde, o discurso aponta para uma insatisfação do gestor em relação a esse fato, porém afirma ser essa a realidade local. O gestor transfere a 'culpa' para os outros atores sociais, como os trabalhadores, usuários e setor privado sem se perceber corresponsável dessa realidade.

Não queremos desmerecer as limitações e as dificuldades apresentadas pelos gestores, pois é exatamente por essas limitações que se torna fundamental, repensar não apenas no formato da ESF enquanto única possibilidade para reorganização da APS, mas na forma que essa estratégia está sendo encaminhada pelos municípios. Também não podemos negar a importância da implantação das ESF para ampliar o acesso aos serviços de saúde, porém, concordamos com Mattos $^{12}$ que esta iniciativa não é suficiente para a garantia da integralidade das ações e para uma mudança no modelo médico assistencial. Assim, apontamos para a necessidade de ampliar as reflexões sobre a responsabilidade do gestor diante dessa realidade e a sua potência para encaminhar mudanças na forma de produzir saúde.

Em relação ao discurso DSC 2D, o gestor vê a necessidade de atendimento ambulatorial em horário diferenciado a fim de garantir acesso aos serviços de saúde para trabalhadores. Aponta então a coexistência entre um atendimento programado realizado pela equipe de saúde da família e um atendimento de demanda espontânea após o atendimento da referida equipe. Porém, o discurso também apresenta a dificuldade da população em compreender e aceitar um atendimento programado em detrimento do atendimento por livre demanda e neste caso, a comunidade pode direcionar sua procura para a segunda modalidade de atendimento, esvaziando o PSF.

O discurso confirma a afirmativa de Paim ${ }^{18}$ referente à existência de modelos voltados para as demandas espontâneas e para as programadas baseadas nas necessidades de saúde, os quais no Brasil coexistem de forma contraditória ou complementar, porém cabe refletir se essa situação não é fortalecida a partir das próprias estratégias encaminhadas pelo gestor.

Outra questão a ser levantada refere-se à organização dos serviços tomando como base o lo- 
cal de residência. Mattos ${ }^{19}$ traz uma reflexão sobre essa questão ao apontar que na prática nem sempre a proximidade do local de residência facilita o acesso, porém, muitas vezes, os serviços são organizados sem levar em consideração os fluxos do cotidiano das comunidades, tanto no que se refere ao local da oferta dos serviços, quanto ao horário que esses serviços são ofertados.

Assim, para uma população que passa o dia inteiro trabalhando distante de sua residência, a organização dos serviços embasada nos locais de moradia não significaria necessariamente, uma garantia de acesso. Pelo contrário, pode tornarse um empecilho para que esse usuário seja atendido em algum serviço de saúde que ele tiver condições de procurar, respeitando a sua rotina de vida. Merhy et al. ${ }^{20}$ questionam o formato único para o PSF, o qual não estaria levando em consideração as especificidades locais e regionais.

O discurso aponta ainda para o fato dos municípios ofertarem salários maiores para atrair profissionais que já estão atuando em municípios vizinhos, criando assim atritos intermunicipais e contribuindo para a rotatividade de pessoal. Entendemos que este aponta para a manutenção de uma relação intermunicipal concorrencial, o que vai ao encontro da lógica do livre comércio e à concorrência do mercado. Porém se apresenta contrária à lógica do processo de descentralização cooperativo e ao fortalecimento da regionalização da saúde (reafirmando a soberania do mercado).

O DSC 3 referente ao atendimento ao usuário como uma das ações realizadas pelos secretários de saúde aponta para a forma como o gestor percebe o seu atendimento ao usuário. Por um lado apresenta um atendimento enquanto intervenção técnica que objetiva agilizar os serviços a partir da liberação de procedimentos, insumos e outros ou ainda prevê ouvir reclamações e sugestões. Por outro lado, resgata a representação de um atendimento enquanto intervenção humanitária, na medida em que propõe a ajuda ao próximo e consequentemente sentir-se útil.

Ambas as situações trazem a representação de que o gestor é o responsável por atender as expectativas do usuário. Ao aproximar essa situação à lógica de uma sociedade consumidora, podemos associar os usuários a consumidores que buscam estratégias para satisfazer seus desejos de forma ágil, isto é, garantir o acesso aos serviços de saúde almejados, e encontram no atendimento direto do gestor, a alternativa mais eficaz. Esses por sua vez, disponibilizam rapidamente as 'mercadorias de desejo', conferindo agilidade ao processo e mantendo o 'usuário-consumidor' num grau aceitável de satisfação. A confirmação de que esse grau de satisfação foi atendido apresenta-se no discurso que afirma que 'quanto mais você atende mais gente tem pra atender' e assim, aumenta-se o número de consumidores que assumem a referida estratégia. Esta tríade (usuárioserviço-gestor) se apresenta como necessária para a manutenção de uma sociedade de consumidores, na medida em que movimenta o 'mercado de serviços de saúde' e concomitantemente inibe as insatisfações e os questionamentos em relação aos mecanismos utilizados para alcance de serviços de saúde como um direito.

Esse mecanismo, por sua vez, reflete a representação de que o bom 'usuário-consumidor' é aquele que tem acesso aos serviços, independente da estratégia utilizada para tal. Nesse sentido, o discurso expressa a utilização de mecanismos de pressão por parte da população para a obtenção de suas solicitações. Emerge a representação de que o usuário é capaz de se utilizar de iniciativas singulares e individualizadas para conseguir seus desejos, além de estimular a concorrência e a competitividade entre os municípios, também frutos do livre comércio.

A necessidade de atender as solicitações dos usuários também expressa a relação da população com os representantes governamentais. Para o gestor, o que prevalece, prioritariamente nos municípios do interior, é a relação com bases assistencialistas e clientelistas historicamente legitimadas no Brasil. Entendemos que esta forma de oferta de serviços contribui para desresponsabilizar o Estado de garantir o direito à saúde, ainda que afirmado constitucionalmente, e transferir esta responsabilidade para os gestores. Neste caso, os serviços de saúde seriam obtidos a partir de relações pessoais. Assim, se os serviços de saúde, não forem disponibilizados para atender às necessidades-desejos dos consumidores da saúde, os gestores poderão ser culpabilizados e, consequentemente, descartados, sem prejuízo das instituições governamentais.

O discurso afirma que a maior parte dos atendimentos está relacionada à liberação de serviços assistenciais como consultas, exames e cirurgias. Este fato nos leva ao questionamento se o usuário realmente busca prioritariamente esse tipo de serviços ou se o gestor valoriza mais essas solicitações e consequentemente, expressa em seu discurso. Entendemos que as duas afirmativas estão presentes o que fortalece a ideia de que o modelo médico assistencial ainda se mantém hegemônico em decorrência do próprio encami- 
nhamento dado por todos os atores envolvidos na produção de saúde.

Em relação às dificuldades enfrentadas para garantir o acesso (IC 4), o discurso aponta para a procura de indivíduos de um município por serviços disponibilizados em outro município, ocupando as vagas e limitando o acesso dos próprios munícipes, interferências políticas, judicialização associada a interesses das indústrias farmacêuticas entre outros.

No que se refere à procura por serviços de indivíduos em outros municípios, partimos da afirmativa que a saúde é um direito do cidadão, assim ele pode procurar o serviço onde quiser, por outro lado, também existem os limites financeiros, estruturais e humanos dos municípios que impõem limites para garantir esse acesso universal, também apontado no discurso. Porém, o que chamamos a atenção não é apenas para essa contradição, mas sim para uma reflexão sobre os motivos que levam os indivíduos a procurar serviços em outros municípios que não são os de sua residência sem um fluxo organizado.

Cabe neste contexto, apontar três possibilidades; a primeira refere-se ao fato de que o seu município de residência não atende as suas necessidades, assim não garante o acesso nem uma atenção integral e a segunda, refere-se à falta de participação social na construção de fluxos de atenção, assim ele não sabe qual é o caminho que ele deve percorrer para ter sua necessidade atendida. Ou ainda, o arranjo regional organizado pelo gestor não é o ideal sob a perspectiva da população. Independente de qual for a causa, podemos perceber que há uma fragilidade em relação aos fluxos de atenção organizados pela gestão, comprometendo a garantia de um acesso resolutivo.

Para Mattos ${ }^{19}$ negar os serviços para indivíduos de outros municípios "é apenas o exercício do poder de vedar o acesso aos serviços de saúde demandados", sendo uma possível consequência a procura pelos planos de saúde por parte dos usuários que não tiveram acesso ao serviço que pensava necessitar. Essa possibilidade vem reforçar os interesses das instituições privadas e concomitantemente fragiliza o sistema público na medida em que direciona a população com maior poder aquisitivo para a medicina suplementar ${ }^{21}$. Entendemos que é necessário fortalecer as relações intermunicipais e interfederativas e a participação social para a construção de redes de atenção que realmente vão ao encontro das necessidades dos usuários.

Em relação à judicialização, na representação do gestor trata-se de uma ação que nega as filas de espera e que fortalece os interesses das indústrias farmacêuticas, dificultando assim, o acesso universal e a efetivação da integralidade. Em contra ponto, Mattos $^{22}$ faz uma distinção entre a ação judicial voltada para os interesses do mercado, que defendem interesses individuais e a aquela voltada para garantir o legítimo direito do cidadão. Ainda, aponta para a possibilidade dos processos judiciais contribuírem para uma reorientação dos serviços de saúde com vistas a aproximá-los às necessidades da população. No entanto, na representação do gestor, a judicialização se mantém atrelada a uma demanda individual em detrimento de se tornar um processo social.

Entendemos que a judicialização é uma possibilidade que pode limitar a efetivação dos princípios do SUS e contribuir para a lógica do mercado, na medida em que favorece as empresas privadas de prestação de serviços e indústrias farmacêuticas e contribui para transformar o usuário que até então, se apresenta enquanto um 'consumidor falho' em um 'consumidor eficiente' e assim, valorizar os interesses individuais.

No entanto, acessar os órgãos responsáveis pela abertura de processos judiciais também exige eficiência por parte do consumidor, trazendo novamente uma distinção entre os falhos e os eficientes, isto é, entre aqueles que têm conhecimento e que conseguem buscar os órgãos competentes. Esta distinção que separa aqueles que conseguem acessar a judicialização e os que se mantêm alheios inclusive a este processo, mais uma vez, impede a garantia do direito à saúde de forma universal.

A judicialização também pode impulsionar o sistema de saúde com vistas a uma transformação das práticas e à consolidação do SUS a partir do momento que possibilita a garantia do direito à saúde que, de outra forma, o sistema não está sendo garantido. Os processos judiciais também apontam para a relação entre demanda e oferta, o que pode ser utilizado para, de forma responsável, direcionar os serviços de saúde tanto no que se refere à organização dos processos de trabalho quanto à definição de serviços oferecidos. Nesse sentido, os interesses individuais podem contribuir para alcançar os interesses coletivos.

O discurso aponta outros atores envolvidos no processo de judicialização. Referimo-nos às indústrias farmacêuticas que, são consideradas como as beneficiadas pelos mandatos judiciais, reforçando a lógica do mercado e sobrepondo seus interesses aos da população.

E ainda, aponta para o papel do médico que, a partir do seu poder legitimado socialmente e 
cientificamente, direciona sua prática em seu cotidiano para também beneficiar os interesses do mercado. Essa postura do profissional também reflete o entendimento de que o mesmo apesar de trabalhar para o Estado reproduz os interesses do mercado.

Outro ponto apresentado no discurso refere-se à interferência política nas ações de saúde. $\mathrm{Na}$ representação do gestor, se por um lado essa interferência privilegia determinados grupos em relação ao acesso aos serviços de saúde, por outro, é um mecanismo utilizado por eles mesmos para garantir esse acesso em determinados momentos. Ainda que pareça contraditório, a nosso ver, trata-se de uma prática legitimada historicamente no contexto brasileiro e torna-se uma estratégia tanto da população quanto dos gestores para ter as suas necessidades atendidas.

As intervenções de políticos como mais uma estratégia para tornar os 'consumidores falhos' em 'consumidores eficientes' reforçando o entendimento da saúde como um direito de todo cidadão também é apresentada no discurso. Porém, a nosso ver, se os serviços forem capazes de se organizar de forma a responder as necessidades da população e os atores envolvidos tiverem uma participação ativa nessa construção, fortalecendo o sentimento de pertencimento de cada um, a interferência política e as ações judiciais se tornarão desnecessárias. Nesse sentido, acreditamos que a efetivação de uma atenção integral pode ser um caminho para eliminar, ou ao menos, minimizar os efeitos dessas estratégias.

A associação das dificuldades apresentadas no discurso para a garantia do acesso reflete a relação entre os três poderes instituídos no país, a relação entre o Estado e o mercado e o papel do profissional e aponta para a fragmentação e a disputa de poderes que perpassa a produção de saúde e que a distancia, muitas vezes, dos interesses da população. São essas tensões, entre diferentes interesses, que permeiam o cotidiano do gestor e que tornam a produção de saúde um grande desafio.

\section{Considerações finais}

Observamos que a saúde é apontada prioritariamente como um produto que privilegia os interesses do mercado, distanciando-se do entendimento de que se trata de um direito garantido constitucionalmente. Nesse sentido, confirma-se as tensões presentes para a consolidação do SUS em um contexto em que se valoriza o sujeito consumidor em detrimento do cidadão.
Os DSC indicam a garantia de acesso aos serviços de saúde em todos os níveis de atenção, com ênfase na média e alta complexidade, como a maior preocupação dos gestores. Porém a qualidade, a resolutividade, a aproximação com as necessidades reais do usuário e a organização das redes de atenção são muito pouco expressas. Também não apontam uma preocupação com a oferta de serviços de prevenção de doenças, promoção da saúde e tratamento em todos os níveis de atenção, fundamental para a garantia de uma atenção integral. Reflete um entendimento limitado e fragmentado que não leva em consideração o 'acesso de qualidade', o que para nós referese a um entendimento de acesso limitado que não necessariamente irá ao encontro das reais necessidades da população.

Apesar de algumas iniciativas para implantar modelos assistenciais alternativos, os serviços de saúde na micro São Mateus, se mantêm organizados a partir do modelo médico assistencial e aponta a centralidade no conjunto de necessidades voltadas para a garantia do acesso às tecnologias para melhorar ou prolongar a vida. Não queremos com isso negar as limitações apresentadas para a garantia do acesso aos serviços de saúde. Tampouco não podemos negar que o gestor vive em constante tensão entre os interesses da população e os dos grupos que detém o poder instituído, os quais coexistem e tornam a produção de saúde um grande desafio. Porém, entendemos que o gestor assume uma postura passiva tanto na sua relação entre os demais entes federados e representantes dos demais poderes, quanto no encaminhamento das políticas públicas no âmbito municipal.

Entendemos que o gestor tem potência para intervir e gerar mudanças no encaminhamento das políticas públicas tanto a partir de práticas que fortaleçam os espaços formais de pactuação, como os Colegiados de Gestão Regional, Conselhos de Secretários de Saúde, Conselhos Municipais de Saúde, mesa de negociação entre outros, quanto no encaminhamento de iniciativas singulares que contribuam para o encaminhamento de um modelo de atenção à saúde que ultrapasse o caráter biomédico e vá em direção de uma atenção integral à saúde. Para tanto torna-se necessário que os gestores se entendam como protagonistas e corresponsáveis na condução das políticas públicas de saúde, o que , para nós, configura-se em uma posição pró ativa dos mesmos.

Compreendemos que a impotência apresentada pelos gestores para gerar mudanças e a falta de participação da sociedade e dos trabalhado- 
res na gestão fortalecem a supremacia dos interesses do mercado e contribuem para a garantia de um 'acesso limitado', a manutenção do modelo de atenção vigente e, em última instância, a reprodução da sociedade de consumidores.

\section{Colaboradores}

BFS Silva trabalhou na concepção, no delineamento, na análise e na interpretação dos dados; na redação do artigo e na aprovação da versão a ser publicada. GAV Benito trabalhou na concepção, no delineamento, na análise e na aprovação da versão a ser publicada. 


\section{Referências}

1. Bauman Z. Vida para consumo: a transformação das pessoas em mercadorias. Tradução de Carlos Alberto Medeiros. Rio de Janeiro: Jorge Zahar Ed; 2008.

2. Lecovitz E, Lima LD, Machado CV. Política de saúde nos anos 90: relações intergovernamentais e o papel das Normas Operacionais Básicas. Cien Saude Colet 2001; 6(2):269-291.

3. Noronha JC, Lima LD, Machado CV. A gestão do Sistema Único de Saúde: características e tendências. In: Ministério da Saúde (MS). Saúde no Brasil: Contribuições para a Agenda de Prioridades de Pesquisa. Brasília: MS; 2004. p. 45-94.

4. Spedo SM, Tanaka OY, Pinto NRS. O desafio da descentralização do Sistema Único de Saúde em município de grande porte: o caso de São Paulo Brasil. Cad Saude Publica 2009; 25(8):1781-1790.

5. Arretche M. Financiamento federal e gestão local de políticas sociais: o difícil equilíbrio entre regulação, responsabilidade e autonomia. Cien Saude Colet 2003; 8(2):331-345.

6. Mendes EV. Avançando no federalismo sanitário brasileiro: a descentralização convergente. In: Keinert TMM, Rosa TEC, Meneguzzo M, organizadores. Inovação e cooperação intergovernamental microrregionalização, consórcio, parcerias e terceirização no setor saúde. São Paulo: Annablume; 2006. p. 13-22.

7. Luz MT. Políticas de Descentralização e Cidadania: Novas Práticas em Saúde no Brasil Atual. In: Pinheiro R, Mattos RA, organizadores. Os sentidos da integralidade na atenção e no cuidado à saúde. Rio de Janeiro: UERJ/IMS, ABRASCO; 2001. p. 17-37.

8. Brasil. Lei no 8.08019 de setembro de 1990 Dispõe sobre a participação da comunidade na gestão do Sistema Único de Saúde (SUS) e sobre as transferências intergovernamentais de recursos financeiros na área da Saúde e dá outras providências. Diário Oficial da União 1990; 19 set.

9. Brasil. Ministério da Saúde (MS). Regionalização da assistência à saúde: aprofundando a descentralização com equidade no acesso. Brasília; MS; 2001.

10. Vasconcelos CM, Pasche DF. O Sistema Único de Saúde. In: Campos GWS, Minayo MCS, Akerman M, Drumond Junior M, Carvalho YA, organizadores. Tratado de saúde coletiva. Rio de Janeiro: Fiocruz, 2006. p. 531-562.

11. Trevisan LN, Junqueira LAP. Construindo o "pacto de gestão" no SUS: da descentralização tutelada à gestão em rede. Cien Saude Colet 2007; 12(4):893 902.

12. Mattos RA. O Incentivo ao Programa de Saúde da Família e seu impacto sobre as grandes cidades. Physis 2002; 12(1):77-108.
13. Fausto MCR, Matta GC. Atenção Primária à Saúde: histórico e perspectivas. In: Morosini MVGC, Corbo ADA, organizadores. Modelos de atenção e a saúde da família. Rio de Janeiro: EPSJV, Fiocruz; 2007. p. 43-67.

14. Merhy EE, Franco TB. Por uma Composição Técnica do Trabalho em Saúde centrada no campo relacional e nas tecnologias leves. Apontando mudanças para os modelos tecnoassistenciais. Saúde em Debate 2003; 27(65):316-323.

15. Lefevre F, Lefevre AMC. Pesquisa de representação social: um enfoque qualiquantitativo: a metodologia do Discurso do Sujeito Coletivo. Brasília: Líber Livro Editora; 2010.

16. Brasil. Ministério da Saúde (MS). Conselho Nacional de Saúde. Resolução nº 196 de 10 de outubro de 1996. Diretrizes e Normas Regulamentadoras de Pesquisas Envolvendo Seres Humanos. Diário Oficial da União 1996; 16 out.

17. Freire P. Pedagogia do oprimido. 12a Edição. Rio de Janeiro: Paz e Terra; 1983.

18. Paim JS. Modelos de atenção e vigilância da saúde. In: Rouquayrol MZ, Almeida Filho N, organizadores. Epidemiologia e saúde. $6^{\text {a }}$ Edição. Rio de Janeiro: MEDSI; 2003. p. 567-586.

19. Mattos RA. Repensando a organização da rede de serviços de saúde a partir do princípio da integralidade. In: Pinheiro R, Mattos RA, organizadores. Razões públicas para a integralidade em saúde: o cuidado como valor. Rio de Janeiro: ABRASCO; 2007. p. 369-383.

20. Merhy EE, Malta DC, Santos FP. Desafios para os gestores do SUS, hoje: compreender os modelos de assistência à saúde no âmbito da reforma sanitária brasileira e a potência transformadora da gestão. In: Freese E, organizador. Municípios: a gestão da mudança em saúde. Recife: UFPE; 2004. p. 45-76.

21. Mattos RA. Princípios do Sistema Único de Saúde (SUS) e a humanização das práticas de saúde. Interface (Botucatu) 2009; 13(Supl.1):771-780.

22. Mattos RA. Direito e saúde: caminhos para universalidade e equidade expositor. In: V Seminário Internacional Direito e Saúde e IX Seminário Nacional Direito e Saúde - mesa de exposições; 2010; Rio de Janeiro.

Artigo apresentado em 11/04/2012

Aprovado em 29/05/2012

Versão final apresentada em 22/06/2012 